\title{
Lung function of healthy boys and girls in Jamaica in relation to ethnic composition, test exercise performance, and habitual physical activity
}

\author{
G. J. MILleR ${ }^{1}$, M. J. SAUNDERS, R. J. C. GILSON, AND M. T. ASHCROFT
}

From the Medical Research Council's Pneumoconiosis Unit, Llandough Hospital, Penarth, South Wales, and Medical Research Council's Laboratories, University of the West Indies, Kingston 7, Jamaica

Miller, G. J., Saunders, M. J., Gilson, R. J. C., and Ashcroft, M. T. (1977). Thorax, 32, 486-496. Lung function of healthy boys and girls in Jamaica in relation to ethnic composition, test exercise performance, and habitual physical activity. The relationships of forced expiratory volume and forced vital capacity on height, age, sex, area of residence, and ethnic composition were assessed in 622 children in Jamaica. Rural children in hill-farming communities were judged to have a higher habitual physical activity than urban children. Allowing for differences in body size, forced vital capacity averaged 3\% greater in rural children than in urban children, $7 \%$ less in girls than in boys, and 16\% greater in children of European origin than in children of African descent.

Lung volumes, indices of gas transfer, and submaximal-exercise responses were measured in a subgroup of 108 children of African descent believed to be of common genetic stock. Total lung capacity and vital capacity averaged respectively $6 \%$ greater and $7 \%$ greater in rural than in urban children of equal height but residual volume and transfer factor did not differ significantly between localities.

Rural children had a lower average cardiac frequency during test exercise than did urban children. Sex differences and locality differences in vital capacity and total lung capacity disappeared when allowance was made for standardised exercise cardiac frequency. At standard body size and age transfer factor increased with decreasing cardiac frequency for standard work.

The results suggest an harmonious development of the cardiac and respiratory components of the oxygen transport system, consonant with the demand for muscular work. Increased habitual physical activity and improved exercise performance appear to be associated with increases in vital capacity, total lung capacity, and transfer factor.

The contributions of sex, ethnic group, and habitual physical activity to lung function during childhood are not so well documented as are those in adulthood. Information on differences between boys and girls is practically confined to children of European descent (Cotes, 1975). Data for children of African origin (Smillie and Augustine, 1926; Roberts and Crabtree, 1927; Harden et al., 1965; Huizinga and Glanville, 1968) suggest that, as with adults (Edwards et al., 1972), vital capacity

1Present address: MRC External Scientific Staff, Caribbean Epidemiology Centre (CAREC), PO Box 164, Port of Spain, Trinidad is smaller than that for Europeans of equal height, but to date there appears to be no published direct comparison of children belonging to these ethnic groups.

Physically active children in Europe (Astrand et al., 1963; Andrew et al., 1972) and in New Guinea (Anderson et al., 1974) have a larger height-standardised vital capacity than their less active compatriots, but important genetic differences between the active and less active groups have not been excluded. Athletic children might self-select themselves because of inherited physical attributes (Andrew et al., 1972), and in New 
Guinea the active highland children and less active coastal children, who have been isolated from each other until recent years, are genetically distinct in some respects (Beaven et al., 1972; Harvey, 1974). Ekblom (1969) studied the effects of physical training on boys. Although no apparent effect was observed after six months, the results did suggest increased lung growth and development after 32 months' training. The author noted, however, that those who trained for the full period had the larger vital capacity even before the beginning of training.

A consideration of the effects of sex, ethnic origin, and physical activity on lung function is important in those parts of the world, such as the Caribbean, where there exist large differences in ethnic background and way of life within populations. The present study was undertaken in Jamaica in order to assess the contributions made by these characteristics to variation in lung function and exercise performance during childhood.

\section{Background}

Kingston, the capital of Jamaica, lies on the southwestern coastal plain and is bounded inland by the rugged foothills of the Blue Mountain Range. Children born and bred in the city live within a few miles of others reared in small hill-farming communities which populate the rural mountain areas. Long-standing internal migration has ensured that urban and rural children of African origin are of common genetic stock. In the urban areas, but not in the rural districts, children of African and of European descent live alongside each other.

Urban children were drawn from two schools. The first was a government primary school which admitted children from 5 years. Most but not all had left by 13 years. In general, these pupils belonged to relatively low-income families. The great majority walked to school but a few used public transport and the occasional child travelled by car. Very few had worked on the land and then only during holidays. The second school was a private establishment for children aged 5 to 18 years. Many of its pupils were the sons and daughters of expatriates from North America and Europe, though not infrequently these children had been born locally or brought to Jamaica when very young.

Rural children attended a government all-age school in Gordon Town, a small community situated at an altitude of about $350 \mathrm{~m}$ and some five miles from the Kingston boundary. Most pupils lived either in Gordon Town or in the surrounding hill country, while a minority lived either on the Kingston road or within the city limits. Rural children were defined as those who from birth had resided continuously in the small hill-communities situated at altitudes below $800 \mathrm{~m}$ beyond Gordon Town and distal to Kingston (eg Dublin Castle, Mount Industry, Sugar Loaf). They belonged to families which farmed small-holdings of on average about 2 hectares, and were expected to assist on the land after school, on Fridays in preparation for market, and at weekends. The steepness of the terrain and lack of capital precluded mechanisation, and the work was physically demanding. From 5 years of age these rural children walked up to 3 miles between home and school along the tracks and bridle-paths which follow the many ridges and gullies in the area. Gordon Town has always had access to Kingston and nowadays is served by public transport from the city.

Miscegenation between the immigrant African and European peoples of Jamaica is more evident in the urban areas than in rural districts, but everywhere people of predominantly or entirely African descent form the great majority.

\section{Subjects and methods}

Six hundred and fifty-two children were examined satisfactorily. Although very likely to be representative of their kind they did not represent a random sample of the school populations. In Jamaica primary education is not compulsory and school admission registers do not necessarily tally with current attendance. Because time did not permit preliminary private censusing, children were simply called ad hoc from the registers of the day until sufficient numbers had been examined. Children who had resided in both urban and rural districts of Jamaica were not accepted for study. Those examined were grouped according to area of residence as being either urban (within the city limits), rural (defined above), or semi-rural (mainly Gordon Town and the Gordon Town to Kingston road).

In the urban and rural government schools date of birth was obtained from the birth certificate as recorded in the admission registers. In the private establishment children were asked their date of birth. Since lung function during childhood has been reported to be better correlated with stature than with age (Cotes, 1975), and rural children tend to be shorter than urban children relative to chronological age (Ashcroft and Lovell, 1964; Standard et al., 1969), height differences between 
Table 1 Survey population according to sex, area of residence, age, and ethnic group

\begin{tabular}{|c|c|c|c|c|c|c|c|c|}
\hline & \multicolumn{4}{|l|}{ Boys } & \multicolumn{4}{|l|}{ Girls } \\
\hline & Urban* & Semirural & Rural $†$ & Totals & Urban ${ }^{*}$ & Semirural & Rural $†$ & Totals \\
\hline \multicolumn{9}{|l|}{ Age (yr) } \\
\hline $7-$ & 37 & 3 & 5 & 45 & 39 & 4 & 5 & 48 \\
\hline 9- & 146 & 11 & 31 & 188 & 98 & 7 & 17 & 122 \\
\hline $11-$ & 81 & 14 & 26 & 121 & 68 & 5 & 33 & 106 \\
\hline $13-14$ & 1 & 2 & 7 & 10 & 1 & 1 & 10 & 12 \\
\hline \multicolumn{9}{|l|}{ Ethnic group +} \\
\hline 0 & 99 & 24 & 62 & 185 & 92 & 16 & 52 & 160 \\
\hline $0.25-0.75$ & 83 & 6 & 7 & 96 & 58 & 1 & 12 & 71 \\
\hline 1 & 63 & $\mathbf{0}$ & 0 & 63 & 47 & 0 & 0 & 47 \\
\hline Other & 20 & 0 & 0 & 20 & 9 & 0 & 1 & 10 \\
\hline Totals & 265 & 30 & 69 & 364 & 206 & 17 & 65 & 288 \\
\hline
\end{tabular}

*Within city boundary.

+Outside Gordon Town limits and distal to Kingston.

$\ddagger \quad 0=$ African;

$0 \cdot 25-0 \cdot 75=$ Afro-European

$1=$ European.

the groups were minimised by selecting the rural group to be about 6 to 9 months older than the urban group.

Ethnic composition was assessed by one observer (MTA) from complexion, features, and, when necessary, a family history. Those judged to be of other than European or African stock or both were excluded from study. Children were examined at school during normal hours of attendance after consent had been given by parent or guardian.

\section{ANTHROPOMETRY}

All anthropometric measurements were made in accordance with the recommendations of the Human Adaptability Sub-committee of the International Biological Programme (Weiner and Lourie, 1969). Sitting and standing heights (cm) were measured with a stadiometer (Holtain) and weight (kg) was recorded on a balance scale. Arm and calf circumferences $(\mathrm{cm})$ were measured with a steel tape, and skinfold thickness was estimated over triceps and the medial calf with Harpenden calipers (Holtain). Chest diameter $(\mathrm{cm})$ in the nipple-line at functional residual capacity and subscapular skinfold thickness $(\mathrm{mm})$ were measured in boys only.

\section{VENTILATORY CAPACITY}

Forced maximum expiratory flow rate (MEFR 1 $\min ^{-1}$ ) was measured with a Wright peak flow meter (Wright and McKerrow, 1959). The forced expiratory volume in one second $\left(\mathrm{FEV}_{1}\right)$ and forced vital capacity (FVC) were recorded with a low-resistance dry-spirometer (Collins et al., 1964) and expressed in litres BTPS. For each index the mean of three technically satisfactory performances was used in the analysis. Many rural children required more practice than urban children in order to acquire the technique.

\section{LUNG VOLUMES AND GAS TRANSFER}

The major purpose of the study was to assess the effects of a rural way of life on lung function and exercise performance. Since all but 19 rural children were of African origin further study had to be confined to this ethnic group. After further exclusion of children less than $136 \mathrm{~cm}$ in height, those who failed to complete the additional tests satisfactorily, and two children with obvious airways obstruction (one with bronchiectasis and the other with exercise-induced asthma), results were obtained for 29 urban boys, 25 urban girls, 30 rural boys, and 24 rural girls.

All 108 children were examined during the morning at least 2 hours after breakfast. Transport was provided between school and the MRC laboratories in Kingston where all further measurements were made. In order to reduce any effects of systematic error urban and rural children attended on alternate weeks. Laboratory air temperature ranged from 21 to $27^{\circ} \mathrm{C}$ with a relative humidity of approximately $70 \%$.

A brief smoking history was taken and then five skinfolds (biceps, triceps, subscapular, suprailiac, anterior thigh) and three limb circumferences (arm, thigh, calf) were measured in the recommended manner (Weiner and Lourie, 1969). 
Fat-free mass (FFM, kg) was estimated from skinfold thickness and weight using the relationships of Durnin and Rahaman (1967). Lung volumes and transfer factor were measured in an uprightseated posture using standard techniques (Cotes, 1975) and a semi-automated apparatus (Resparameter, P. K. Morgan, Ltd). Total lung capacity was measured by the closed-circuit helium-dilution method. The single breath carbon monoxide trans-

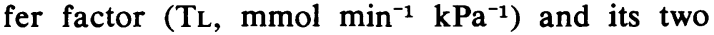
sub-divisions, the diffusing capacity of the alveolar-capillary membrane (Dm, $\mathrm{mmol} \mathrm{min}^{-1}$ $\mathrm{kPa}^{-1}$ ) and alveolar capillary blood volume (Vc, $\mathrm{ml}$ ) were estimated by measuring $T_{L}$ at high and normal alveolar oxygen tensions. The transfer factor was calculated at an alveolar volume obtained by summing the volume of the single breath and the residual volume given by helium dilution (Ogilvie et al., 1957). Haemoglobin concentration was assumed to be $14.6 \mathrm{~g} \mathrm{dl}^{-1}$.

\section{EXERCISE PERFORMANCE}

Each child remained in the laboratory for at least $45 \mathrm{~min}$ (during which lung function was measured) before performing test exercise, after which time skin temperature was assumed to have stabilised in the conditioned air. Skin temperature was then measured at three sites (biceps, subscapular and supra-iliac) with an electronic battery-powered thermometer (Dependatherm) after the child had been seated on a child's cycle ergometer (Monark) and familiarised with the test procedure. The mean of these measurements was used in the analysis. After 2 minutes at rest, progressive submaximal exercise was performed for between 5 and 7 minutes during which the power output was raised by 10 to $12 \mathrm{~W}$ each minute. Pedal frequency was displayed on a ratemeter and maintained at approximately $50 \mathrm{~min}^{-1}$. The child inhaled through a dry-gas meter (Parkinson and Cowan CD4) and low-resistance valve box (Bannister and Cormack, 1954) and exhaled to atmosphere through a gasmixing chamber from which a sample was drawn continuously through a paramagnetic oxygen analyser (Servomex, OA 150) and an infra-red $\mathrm{CO}_{2}$ analyser (Hartmann and Braun). Meters were calibrated before each run with known gas mixtures. The electrocardiogram was continuously displayed on an ultraviolet recorder (Visigraph-P; San-Ei Instruments). These data were used to calculate by interpolation the cardiac frequency $\left(\mathrm{fC}_{33.5}, \mathrm{~min}^{-1}\right)$ and ventilation $\left(\mathrm{Ve}_{33.5} 1 \mathrm{~min}^{-1}\right.$, BTPS) at an oxygen consumption of $33.5 \mathrm{mmol}$ $\min ^{-1}\left(0.751 \mathrm{~min}^{-1}\right.$ STPD), and the tidal volume at a ventilation rate of $301 \mathrm{~min}^{-1}$ BTPS (cf Cotes, 1972).
STATISTICAL ANALYSIS

In the first stage of the analysis, children were grouped according to sex, ethnic group, and area of residence, and each group numbering more than 25 was considered separately. The associations of age, standing height, sitting height, weight, and estimated fat-free mass with the indices of lung function and exercise performance were then explored by multilinear regression analysis after all variates had been transformed to natural logarithms.

Secondly, each group characteristic was coded as a 'dummy variate' as follows:

Sex: male $=0$; female $=1$.

Ethnic composition: African $=0$; European $=1$; intermediate grades as $0.25,0.50$, and 0.75

Area of residence: urban $=0$; semi-rural $=$ $0.5 ;$ rural $=1.0$.

These codes apply whenever these terms appear. Step-down multilinear regression analysis was performed on the data for all children using all continuous independent variates (eg standing height), the dummy variates (eg, sex), and the interaction terms (eg, sex $X$ standing height). The interaction terms were included to test whether the partial regression coefficients on the continuous variates were independent of sex, ethnic composition, and area of residence. Groups could be combined whenever the coefficients on the dummy variate and its interaction term failed to achieve statistical significance at the $5 \%$ level (eg, the relationship between the dependent variate and independent variate was considered not to differ between boys and girls if the dummy variate (sex) and the interaction term (sex $X$ independent variate) failed to achieve statistical significance). The step-down regression procedure handled the sub-set of interaction terms first omitting the least significant of these at each stage until those remaining were all significant at or below the $5 \%$ level. Thereafter the step-down procedure continued on the sub-set of continuous and dummy variates which did not compose any of the significant interaction terms, until only those which were statistically significant remained.

\section{Results}

\section{ANTHROPOMETRY}

Tables 2 and 3 present the ages and physical characteristics of boys and girls respectively according to area of residence and ethnic composition. The results for urban children show that while standing height was independent of ethnic composition, children of European descent had a 
Table 2 Age, anthropometry, and ventilatory capacity of boys according to ethnic origin and area of residence

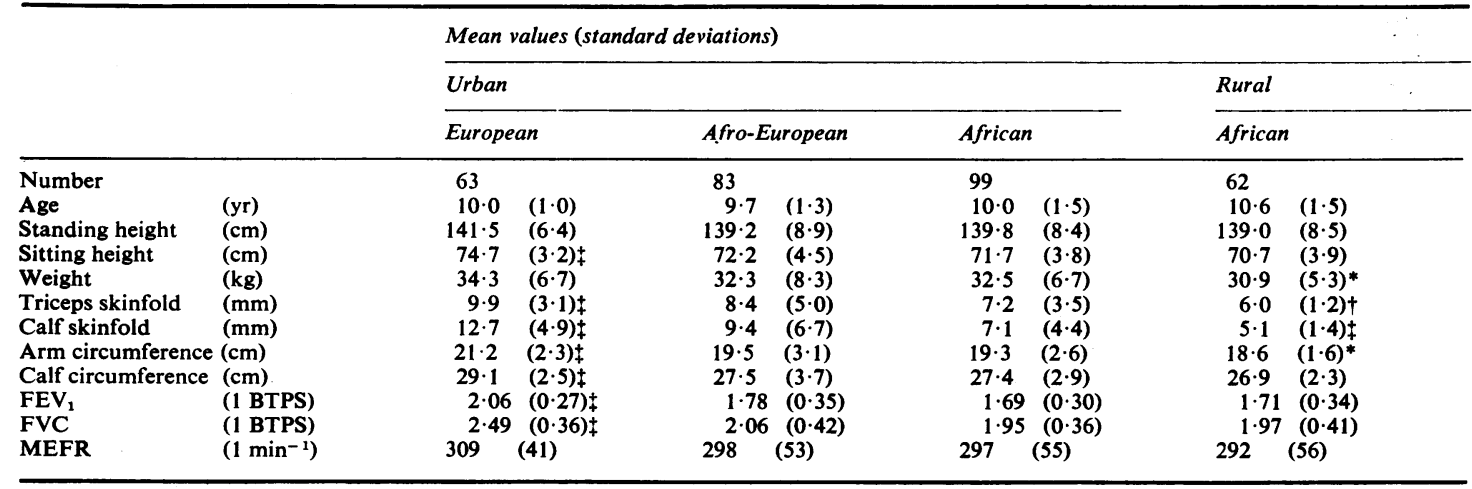

$\mathrm{FEV}_{1}=$ forced expiratory volume in one second.

$F V C=$ forced vital capacity.

MEFR = forced expiratory maximum flow rate.

In the statistical comparison with urban African children using a $t$ test with unequal variances, ${ }^{*} P<0.05 ; \dagger P<0.01 ; \ddagger P<0.001$.

Table 3 Age, anthropometry, and ventilatory capacity of girls according to ethnic origin and area of residence

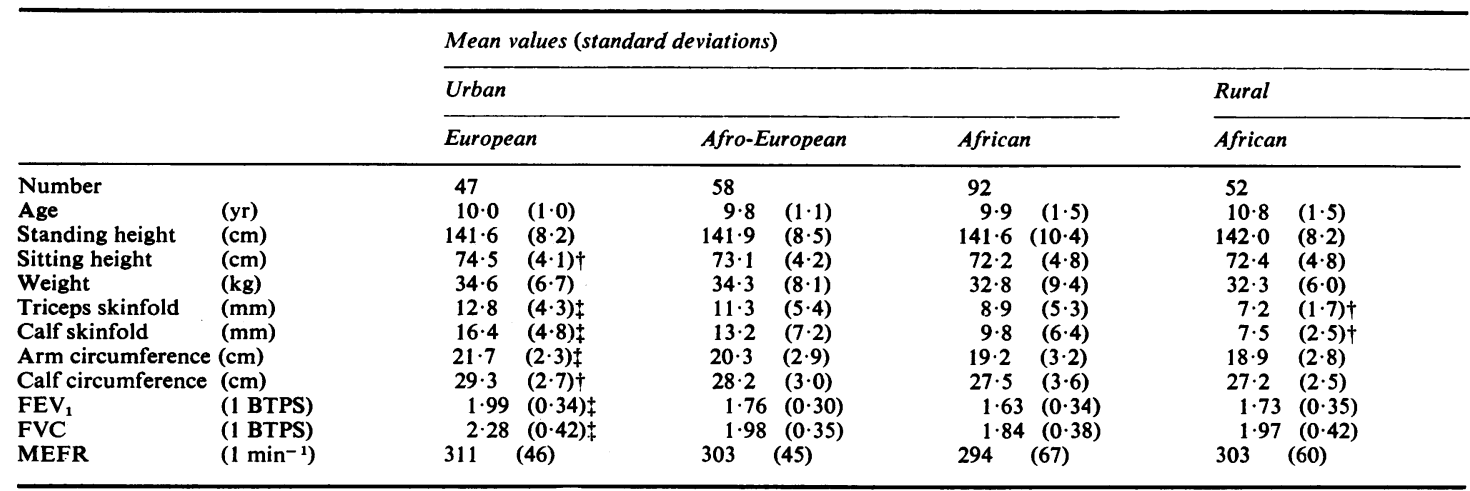

Footnotes as in Table 2.

significantly greater sitting height than those of African descent such that the mean cormic index (sitting height $\div$ standing height) was 0.53 and 0.51 respectively. The European child weighed on average $1.8 \mathrm{~kg}$ more and had significantly greater limb circumferences and skinfold thicknesses than the African child. As a group, children of AfroEuropean descent had intermediate values. Among children of African origin those from rural areas weighed less and had significantly smaller skinfold thicknesses than those from Kingston, even though the rural group was the elder.

In African boys from both areas, but not in African girls, the cormic index decreased with increasing height and age but no significant urbanrural differences were apparent. After combining the groups, average cormic index in boys declined from 0.515 at age 9 years to 0.505 at 12 years, while for girls it averaged 0.508 at all ages.

Boys of European descent had a greater mean subscapular skinfold thickness $(7.7 \mathrm{~mm}$, SD $5 \cdot 1)$ than either the urban or rural group of African boys $(6.6 \mathrm{~mm}$, SD 4.6 , and $5.1 \mathrm{~mm}$, SD $0.8 \mathrm{re}-$ spectively). Multilinear regression analysis showed that at standard sitting height and subscapular skinfold thickness the rural African boy had on average a $1.1 \mathrm{~cm}$ greater chest circumference than the urban African boy $(\mathrm{P}<0.001)$.

\section{VENTILATORY CAPACITY}

Many children had experimented with cigarettes but none had smoked regularly. Tables 2 and 3 
show that in urban children those of European origin had an $\mathrm{FEV}_{1}$ and FVC on average 122 to $128 \%$ that of African children. In children of African descent, rural girls had larger mean values than urban girls (although the increase was not statistically significant) but no urban-rural difference was apparent in boys. Maximum expiratory flow rate appeared independent of sex, ethnic composition, and area of residence.

Multilinear regression analysis showed that both $\mathrm{FEV}_{1}$ and FVC were positively correlated with sitting height and standing height, but that sitting height was the better predictor of ventilatory capacity in this study (that is, it gave the smaller residual standard deviation about the regression line). This was probably because it removed some of the 'nuisance variation' in anthropometric proportions within this group of children of differing ethnic composition. On this account it has been preferred to standing height in this analysis. Also, a better fitted regression was obtained when the data were transformed to natural logarithms, and thus the results are presented in this form in Table 4. Significant and positive partial regression coefficients were obtained for both $\mathrm{FEV}_{1}$ and FVC on age and sitting height, and the step-down analysis showed that these coefficients were independent of sex, ethnic composition, and area of residence. However, at standard age and sitting height, the $\mathrm{FEV}_{1}$ was on average $4.3 \%$ less in girls than in boys and $12.5 \%$ greater in children of European descent than in those of African descent but showed no significant urban-rural difference. The height and age standardised FVC was on average $7.2 \%$ less in girls than boys, $16.5 \%$ greater in European children than in African children, and (in contrast to the $\mathrm{FEV}_{1}$ ) $3 \%$ greater in rural children than in urban children.

Maximum expiratory flow rate was positively related to both standing height and sitting height. The relationships were independent of sex and area of residence but differed with ethnic composition in both slope and intercept terms. Prediction was equally good using either height index and was not improved by the inclusion of age as an additional independent variate. The relationships were for children of African descent:

$\log _{e} \mathrm{MEFR}=2.207( \pm 0.123) \log _{\mathrm{e}}$ (standing height) $-5 \cdot 241$; RSD $0 \cdot 147$,

and for children of European descent:

$\log _{e}$ MEFR $=1.553( \pm 0.208) \log _{e}$ (standing height) $-1 \cdot 961$; RSD $0 \cdot 110$.

LUNG VOLUMES AND GAS TRANSFER

Table 5 presents the physique and further lung function in the subgroup of 108 children of African descent according to area of residence. No important differences in the body-size indices were found. The larger total lung capacity in rural children (mean difference not statistically significant) was owing to their larger vital capacity. The transfer factor was on average $14 \%$ larger in rural girls than in urban girls owing to increases in both the diffusing capacity of the alveolar capillary membrane and the alveolar capillary blood volume. By contrast, the gas transfer indices in rural boys did not exceed those of urban boys.

Following logarithmic transformation of the data, step-down multilinear regression analysis revealed that vital capacity, inspiratory capacity, residual volume, and total lung capacity were significantly related to standing height and that

Table 4 Multilinear regressions relating $\log _{\mathrm{e}}\left(F E V_{1}\right)^{*}$ and $\log _{\mathrm{e}}(F V C) \dagger$ to sitting height, sex, ethnic composition, and area of residence in 622 Jamaican children

\begin{tabular}{|c|c|c|c|c|c|}
\hline & & \multicolumn{4}{|c|}{ Dependent variate } \\
\hline & & \multicolumn{2}{|c|}{$\log _{e}\left(F E V_{1}\right)$} & \multicolumn{2}{|c|}{$\log _{e}(F V C)$} \\
\hline $\begin{array}{c}\text { Coefficient terms }( \pm S E) \\
\log _{e} \text { (sitting height, } \\
\log _{e} \text { (age, years) }\end{array}$ & & $\begin{array}{l}+2 \cdot 352 \\
+0 \cdot 146\end{array}$ & $\begin{array}{l}(0.096) \\
(0.042)\end{array}$ & $\begin{array}{l}+2 \cdot 523 \\
+0 \cdot 172\end{array}$ & $\begin{array}{l}(0.096) \\
(0.043)\end{array}$ \\
\hline Sex & $\begin{array}{l}=\text { male } \\
=\text { female }\end{array}$ & -0.044 & $(0.009)$ & -0.075 & $(0.009)$ \\
\hline $\begin{array}{l}\text { Ethnic composition } \\
\text { Area of residence }\end{array}$ & $\begin{array}{l}=\text { African } \\
=\text { European } \\
=\text { urban } \\
5=\text { semirural } \\
0=\text { rural }\end{array}$ & $+0 \cdot 118$ & $(0.012)$ & $\begin{array}{l}+0.153 \\
+0.030\end{array}$ & $(0.012)$ \\
\hline \multicolumn{2}{|l|}{$\begin{array}{l}\text { Constant term } \\
\text { Residual standard deviation }\end{array}$} & \multicolumn{2}{|l|}{$\begin{array}{r}-9 \cdot 782 \\
0 \cdot 107\end{array}$} & \multicolumn{2}{|l|}{$\begin{array}{r}-10 \cdot 406 \\
0 \cdot 105\end{array}$} \\
\hline
\end{tabular}

*Natural logarithm of forced expiratory volume in one second (1 BTPS).

+Natural logarithm of forced vital capacity (1 BTPS).

$\ddagger$ For full code see 'Methods'. 
Table 5 Physique and lung function of 108 urban and rural Jamaican children of African ethnic origin

\begin{tabular}{|c|c|c|c|c|c|c|c|c|c|}
\hline \multirow[b]{4}{*}{$\begin{array}{l}\text { Age } \\
\text { Standing height } \\
\text { Sitting height } \\
\text { Weight } \\
\text { Fat free mass } \\
\text { Vital capacity } \\
\text { Inspiratory capacity } \\
\text { Expiratory reserve volume } \\
\text { Residual volume } \\
\text { Total lung capacity } \\
\text { Transfer factor } \\
\text { Diffusing capacity of } \\
\text { alveolar-capillary membrane } \\
\text { Alveolar-capillary blood } \\
\text { volume }\end{array}$} & \multirow[b]{4}{*}{ 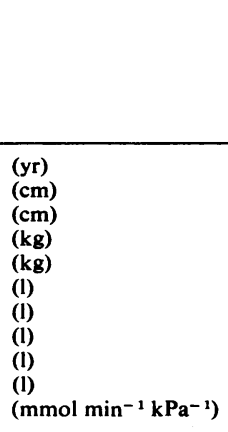 } & \multicolumn{8}{|c|}{ Mean (standard deviation) } \\
\hline & & \multicolumn{4}{|l|}{ Boys } & \multicolumn{4}{|l|}{ Girls } \\
\hline & & \multicolumn{2}{|c|}{ Urban (29) } & \multicolumn{2}{|c|}{ Rural (30) } & \multicolumn{2}{|c|}{ Urban (25) } & \multicolumn{2}{|c|}{ Rural (24) } \\
\hline & & $\begin{array}{c}10 \cdot 8 \\
146 \cdot 4 \\
74 \cdot 8 \\
36 \cdot 4 \\
30 \cdot 8 \\
2 \cdot 07 \\
1 \cdot 30 \\
0 \cdot 77 \\
0 \cdot 56 \\
2 \cdot 63 \\
5 \cdot 8 \\
9 \cdot 3 \\
66\end{array}$ & $\begin{array}{l}(0 \cdot 8) \\
(5 \cdot 1) \\
(2 \cdot 6) \\
(7 \cdot 5) \\
(4 \cdot 0) \\
(0 \cdot 27) \\
(0 \cdot 21) \\
(0 \cdot 17) \\
(0 \cdot 19) \\
(0 \cdot 36) \\
(1 \cdot 3) \\
(3 \cdot 0) \\
(27)\end{array}$ & $\begin{array}{c}11 \cdot 7 \\
146 \cdot 4 \\
74 \cdot 5 \\
35 \cdot 0 \\
31 \cdot 2 \\
2 \cdot 17 \\
1 \cdot 34 \\
0 \cdot 84 \\
0 \cdot 60 \\
2 \cdot 78 \\
5 \cdot 8 \\
9 \cdot 2 \\
55\end{array}$ & $\begin{array}{l}(1 \cdot 1) \\
(5 \cdot 3) \\
(2 \cdot 3) \\
(4 \cdot 4) \\
(3 \cdot 6) \\
(0 \cdot 38) \\
(0 \cdot 37) \\
(0 \cdot 23) \\
(0 \cdot 21) \\
(0 \cdot 47) \\
(1 \cdot 3) \\
(2 \cdot 5) \\
(20)\end{array}$ & $\begin{array}{c}10 \cdot 8 \\
145 \cdot 2 \\
73 \cdot 5 \\
35 \cdot 0 \\
28 \cdot 9 \\
1 \cdot 82 \\
1 \cdot 17 \\
0.65 \\
0.69 \\
2 \cdot 51 \\
5 \cdot 7 \\
10.5 \\
46\end{array}$ & $\begin{array}{l}(0 \cdot 9) \\
(5 \cdot 8) \\
(3 \cdot 3) \\
(9 \cdot 8) \\
(5 \cdot 2) \\
(0 \cdot 26) \dagger \\
(0 \cdot 22)^{*} \\
(0 \cdot 12) \dagger \\
(0 \cdot 18) \dagger \\
(0 \cdot 31) \\
(1 \cdot 1) \\
(3 \cdot 7)\end{array}$ & $\begin{array}{c}11.4 \\
146 \cdot 2 \\
75 \cdot 0 \\
36 \cdot 2 \\
30.8 \\
2.04 \\
1.24 \\
0.79 \\
0.69 \\
2.73 \\
6.5 \\
\\
11 \cdot 6 \\
56\end{array}$ & $\begin{array}{l}(1 \cdot 2) \\
(5 \cdot 8) \\
(3 \cdot 6) \\
(9 \cdot 6) \\
(7 \cdot 8) \\
(0 \cdot 29) \ddagger \\
(0 \cdot 23) \\
(0 \cdot 18) \\
(0 \cdot 26) \\
(0 \cdot 47) \\
(1 \cdot 6) \\
(4 \cdot 5)^{*} \\
(20)\end{array}$ \\
\hline
\end{tabular}

*Boys $v$ girls of same locality, $\mathrm{P}<0.05$.

†Boys $v$ girls of same locality, $P<0.01$.

‡Urban $v$ rural girls, $\mathrm{P}<0.01$.

Table 6 Regression relationships describing lung volumes in terms of standing height, area of residence, and sex in 108 Jamaican children of African descent

\begin{tabular}{|c|c|c|c|c|c|c|c|c|}
\hline \multirow[b]{3}{*}{$\begin{array}{l}\text { Coefficient terms }( \pm S E) \text { on: } \\
\left.\quad \log _{e} \text { (standing height, } \mathrm{cm}\right) \\
\text { Area of residence* } \\
\text { Sex } \dagger \\
\text { Constant term } \\
\text { Residual standard deviation }\end{array}$} & \multicolumn{8}{|c|}{ Dependent variate } \\
\hline & \multicolumn{2}{|c|}{$\begin{array}{l}\log _{\mathrm{e}}(\text { vital } \\
\text { capacity, } 1)\end{array}$} & \multicolumn{2}{|c|}{$\begin{array}{l}\log _{\mathrm{e}} \text { (inspiratory } \\
\text { capacity, 1) }\end{array}$} & \multicolumn{2}{|c|}{$\begin{array}{l}\log _{\mathrm{e}}(\text { residual } \\
\text { volume, } 1)\end{array}$} & \multicolumn{2}{|c|}{$\begin{array}{l}\log _{\mathrm{e}}(\text { total lung } \\
\text { capacity }, 1)\end{array}$} \\
\hline & $\begin{array}{r}\mathbf{2} .283 \\
+0.067 \\
-0.083 \\
-\mathbf{1 0 . 6 7 7} \\
0.120\end{array}$ & $\begin{array}{l}(0 \cdot 313) \\
(0.023) \\
(0.023)\end{array}$ & $\begin{array}{r}+2.862 \\
-\overline{0.072} \\
-14.012 \\
0.164\end{array}$ & $\begin{array}{l}(0.428) \\
(0.031)\end{array}$ & $\begin{array}{r}+2.825 \\
+\overline{0.201} \\
-14.687 \\
0.308\end{array}$ & $\begin{array}{l}(0 \cdot 804) \\
(0 \cdot 060)\end{array}$ & $\begin{array}{r}+2.406 \\
+0.055 \\
-11.052 \\
0.121\end{array}$ & $\begin{array}{l}(0 \cdot 316) \\
(0 \cdot 023)\end{array}$ \\
\hline
\end{tabular}

*Urban $=0$; Rural $=1$.

+ Male $=0$; Female $=1$.

for each index the regression coefficient was independent of sex and area of residence. Furthermore, and in contrast to the finding for FVC in all 622 children, a consideration of age did not improve the prediction of these lung volumes to any appreciable extent. When height-standardised, average vital capacity was $8 \%$ smaller in girls than in boys, and 7\% greater in rural children than in urban children. Total lung capacity appeared independent of sex but when height standardised averaged $5.7 \%$ greater in rural children than in urban children. Very similar results were found when sitting height was employed in place of standing height. No significant urban-rural differences were noted for either inspiratory capacity or residual volume.

Similar analysis of the gas transfer data showed that neither the transfer factor nor its sub-divisions differed significantly with area of residence. All gas transfer indices increased significantly with height, but in each case the regression coefficient $\stackrel{0}{0}$ on height was common to both sexes and to both urban and rural children. For alveolar capillary 8 blood volume the fitted regression was improved $₹$ when estimated fat-free mass was used instead of 을 height, and in this case also the coefficient term applied across all groups. Transfer factor and the diffusion capacity of the alveolar-capillary mem- $\bar{N}$ brane were positively partially correlated with age $\Omega$ in girls but not in boys, the coefficient terms being $N$ independent of area of residence. Alveolar capil- N lary blood volume was not related to age when fat- 0 free mass was taken into account. These results are presented in Table 7 .

EXERCISE PERFORMANCE

Table 8 shows that in both sexes rural children had on average a lower cardiac frequency and $\stackrel{\odot}{\odot}$ minute ventilation during standard exercise than $\mathbb{\mathbb { D }}$ urban children, although these differences were 
Table 7 Regression relationships describing three indices of gas transfer in terms of body size and age in 108 Jamaican children of African descent

\begin{tabular}{|c|c|c|c|c|c|c|}
\hline & \multicolumn{6}{|c|}{ Dependent variate } \\
\hline & $\log _{e} T L$ & & $\log _{e} D m$ & & $\log _{e} V c$ & \\
\hline \multicolumn{7}{|l|}{$\begin{array}{l}\text { Coefficient terms }( \pm S E) \text { on: } \\
\text { In both sexes }\end{array}$} \\
\hline $\begin{array}{l}\log _{\mathrm{e}}(\text { standing height, } \mathrm{cm}) \\
\log _{\mathrm{e}} \text { (fat-free mass, kg)* }\end{array}$ & $\div 2 \cdot 050$ & $(0 \cdot 518)$ & $\begin{array}{c}3.040 \\
-\end{array}$ & $(0 \cdot 940)$ & $+\overline{0.706}$ & $(0 \cdot 260)$ \\
\hline $\begin{array}{l}\text { In girls only } \\
\log _{e} \text { (age, years) }\end{array}$ & 0.964 & $(0 \cdot 296)$ & +0.752 & $(0.350)$ & - & \\
\hline Constant term & & & & & & \\
\hline Boys & $-8 \cdot 481$ & & $-12 \cdot 927$ & & +1.561 & \\
\hline Girls & $-10 \cdot 747$ & & $-14 \cdot 554$ & & +1.561 & \\
\hline Residual standard deviation & $0 \cdot 189$ & & $0 \cdot 330$ & & 0.387 & \\
\hline
\end{tabular}

$\mathrm{TL}_{\mathrm{L}}=$ single breath carbon monoxide transfer factor $\left(\mathrm{mmol} \mathrm{min}^{-1} \mathrm{kPa}^{-1}\right)$.

$\mathrm{Dm}=$ diffusing capacity of alveolar capillary membrane $\left(\mathrm{mmol} \mathrm{min} \mathrm{m}^{-1} \mathrm{kPa}^{-1}\right)$.

$\mathrm{Vc}=$ alveolar capillary blood volume $(\mathrm{ml})$.

*As estimated by the method of Durnin and Rahaman (1967).

†Age did not significantly improve the prediction of either TL or Dm in boys.

Table 8 Means $(S D)$ of indices of exercise performance in 108 urban and rural children of African descent

\begin{tabular}{|c|c|c|c|c|c|c|c|c|}
\hline \multirow{4}{*}{$\begin{array}{l}\text { At an oxygen uptake of } 33.5 \mathrm{mmol}^{\mathrm{min}-1} \text { : } \\
\begin{array}{l}\text { Cardiac frequency } \\
\text { Ventilation }\end{array}\left(\mathrm{min}^{-1}\right) \\
\end{array}$} & \multicolumn{4}{|l|}{ Boys } & \multicolumn{4}{|l|}{ Girls } \\
\hline & \multicolumn{2}{|c|}{ Urban (29) } & \multicolumn{2}{|c|}{ Rural (30) } & \multicolumn{2}{|c|}{ Urban (25) } & \multicolumn{2}{|c|}{ Rural (24) } \\
\hline & $\begin{array}{l}126 \\
21 \cdot 3\end{array}$ & $\begin{array}{l}(12) \\
(2 \cdot 4)\end{array}$ & $\begin{array}{l}122 \\
20 \cdot 8\end{array}$ & $\begin{array}{l}(13) \\
(2 \cdot 1)\end{array}$ & $\begin{array}{l}145 \\
23 \cdot 4\end{array}$ & $\begin{array}{c}(14)^{*} \\
(5 \cdot 1)\end{array}$ & $\begin{array}{r}136 \\
21.9\end{array}$ & $\begin{array}{r}(13)^{*}+ \\
(2 \cdot 6)\end{array}$ \\
\hline & & & & & & & & \\
\hline
\end{tabular}

*Girls $v$ boys of same locality, $\mathrm{P}<0.001$.

† Rural $v$ urban girls, $\mathrm{P}<0.05$.

statistically significant only for cardiac frequency in girls. Tidal volume showed no urban-rural difference.

Linear regression analysis after log transformation of the data showed that exercise cardiac frequency was inversely related to estimated fat-free mass and that the regression coefficient did not differ between sexes or localities. At standard fatfree mass rural children had on average $4 \%$ lower exercise cardiac frequency than urban children, and girls had a $12 \%$ higher value than boys. Thus the overall relationship was:

$$
\begin{gathered}
\log _{e}\left(\mathrm{fC}_{33.5}=5.64-0.236\left( \pm 0.057 \log _{e}(\mathrm{FEM})\right.\right. \\
-0.041( \pm 0.017) \text {. Area of resistance }+0.114 \\
( \pm 0.018) \text { Sex; RSD 0.09. }
\end{gathered}
$$

Consideration of mean skin temperature did not significantly improve the prediction of exercise cardiac frequency in this study.

RELATIONSHIPS BETWEEN LUNG FUNCTION AND EXERCISE CARDIAC FREQUENCY

When standardised exercise cardiac frequency was taken into account all urban-rural and sex differ- ences in the height-standardised lung volumes disappeared. For inspiratory capacity, vital capacity, and total lung capacity the partial regression coefficient on exercise cardiac frequency applied across the sexes and urban and rural groups. These relationships, in which exercise cardiac frequency replaces the dummy variates sex and area of residence (see Table 6), are presented in Table 9. Residual volume was not correlated with exercise cardiac frequency. Table 9 also shows that consideration of cardiac frequency revealed a further significant partial regression coefficient of inspiratory capacity on estimated fat-free mass.

At standard height in boys, and standard height and age in girls, the transfer factor decreased as standardised exercise cardiac frequency increased. The partial regression coefficient of transfer factor on cardiac frequency applied across the sexes and urban and rural groups. The relationship was:

$\log _{\mathrm{e}} \mathrm{TL}=1.609( \pm 0.538) \log _{\mathrm{e}}$ (standing height) $-0.475( \pm 0.197) . \log _{e}\left(\mathrm{fC}_{33.5}\right)+0.873$ $( \pm 0.292)$ age in girls-CONSTANT TERM (4.000 in boys; 5.989 in girls); RSD 0.185. 
Table 9 Relationships of lung volumes with indices of body size and submaximal exercise cardiac frequency in 108 urban and rural Jamaican children of African descent

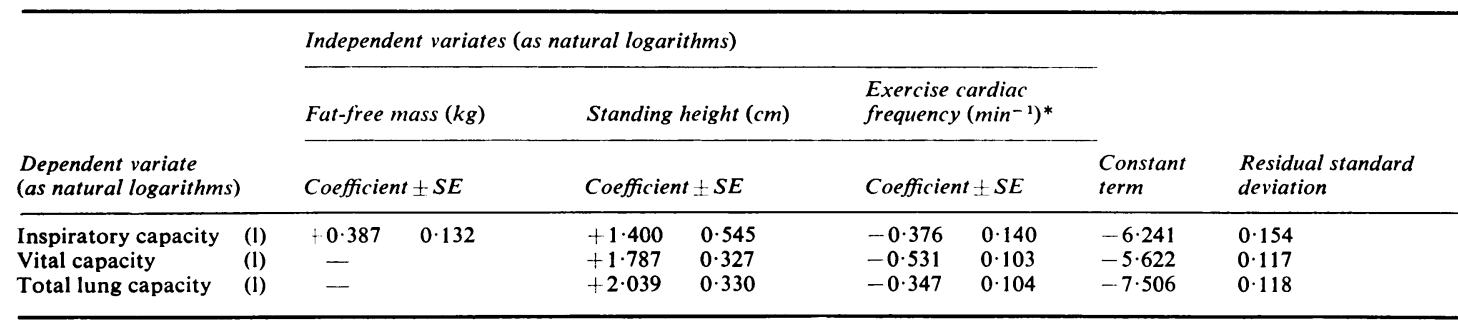

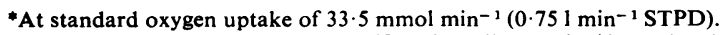

Regression coefficient not presented if statistically not significant $(P>0.05)$.

\section{Discussion}

Table 4 provides further evidence for an ethnic difference in ventilatory capacity as between children of African and of European descent. The larger $\mathrm{FEV}_{1}$ and FVC of European children was common to both sexes. Futhermore, the $4.3 \%$ and $7 \cdot 2 \%$ average reductions in $\mathrm{FEV}_{1}$ and FVC respectively in girls compared with boys were common to both ethnic groups.

Table 10 compares the predicted mean forced vital capacity reported for African, Afro-European, and European children from other parts of the world with values predicted for urban Jamaican children of the same sex, ethnic composition, body size, and age, using the regression in Table 4. Corresponding predicted average values in Jamaica were calculated at a standing height of $137 \mathrm{~cm}$ by converting this to an equivalent sitting height using the average cormic index for

Table 10 Comparison of forced vital capacity (FVC) in urban Jamaican children with that reported for other groups of African, Afro-European, and European descent: results standardised to standing height $137 \mathrm{~cm}$, age 10 years

\begin{tabular}{lll} 
& $\begin{array}{l}\text { Mean } \\
F V C(1)\end{array}$ & $\begin{array}{l}\text { Corresponding mean } \\
F V C \text { in Jamaica }\end{array}$ \\
\hline African: & & \\
$\quad$ Fali/Fulani boys* & $1 \cdot 8$ & $2 \cdot 0$ \\
$\quad$ Kurumba boys $\dagger$ & $1 \cdot 7$ & $2 \cdot 0$ \\
$\quad$ Kurumba girls $\dagger$ & $1 \cdot 6$ & 1.9 \\
Afro-European (Ethiopian) ${ }_{+}^{+}$ & & $2 \cdot 0$ \\
$\quad$ Amhara boys & $2 \cdot 0$ & $2 \cdot 3$ \\
European (UK):§ & $2 \cdot 5$ & $2 \cdot 6$ \\
$\quad$ Boys & $2 \cdot 1$ & $2 \cdot 4$ \\
Girls & & \\
\hline
\end{tabular}

*Huizinga (1976).

†Huizinga and Glanville (1968).

$\ddagger$ Harrison et al. (1969).

$\S$ Cotes et al. (1973a).

All studies were performed using the dry spirometer of Collins $e t$ al. (1964). each ethnic group and multiplying the result by $\stackrel{\circ}{\circ}$ the coefficient term in Table 4. Bearing in mind 음 assumptions regarding ethnic similarity, agree- ment appears to be reasonable.

The usual findings in analyses of this type areç that sitting height confers little if any advantage $\stackrel{\infty}{\rightarrow}$ over standing height in the prediction of venti- $\vec{\omega}$ latory capacity and that after allowance for body $\exists$ size a consideration of age does not further improve the prediction of either $\mathrm{FEV}_{1}$ or FVC (cf Cotes, 1975). This was essentially the case for vital capacity in the sub-group of 108 children of African descent (Table 6). Urban-rural differences in standing height for age and ethnic differences in sitting height for standing height meant that in $\overrightarrow{\overrightarrow{0}}$ the total 622 children simultaneous consideration $\exists$ of sitting height and age provided a better prediction of ventilatory capacity than that afforded by standing height alone (Table 4).

A genetic basis for the urban-rural difference in vital capacity seemed unlikely. The difference in forced vital capacity remained after allowance for ethnic differences using a five-point scale (Table 4). The further study of 108 children was confined to those with characteristics suggesting an exclusively African ethnic background. In this subgroup the cormic index, which is under strong genetic control (Greulich, 1957), showed no tendency in urban children to deviate from that of $N$ rural children towards a value more typical of $N$ European children. The communities from which the children were drawn are only a few miles apart $\omega$ and have always enjoyed free intercommunication, with the result that they are closely assimilated. Thus more probably the difference was due to an environmental factor.

Rural children differ from urban children in their nutritional status, the altitude at which they live and in their level of habitual activity. The shorter stature of children in rural areas than of those in urban areas, relative to chronological 
age, reflects their poorer state of health and nutrition (Ashcroft and Lovell, 1964). While differential growth rates would produce differences in lung function between the groups these have been allowed for in this study, as in others (Huizinga and Glanville, 1968; Cotes et al., 1973b) by relating lung volumes to the appropriate index of body size and age. The difference in altitude of residence, which mounted to less than $1000 \mathrm{~m}$, could not have been responsible for the increased vital capacity of rural children (Goldman and Becklake, 1959).

The remaining environmental factor likely to affect vital capacity was the increased habitual vigorous activity of rural children. Although not directly measured, there can be little doubt that the day-to-day activities of children in the hillfarming communities were physically more demanding than those of urban children. This impression was supported by the responses to test exercise. The training effect of vigorous activity increases the stroke volume of the heart and reduces the cardiac frequency at standard work (Ekblom, 1969; Cotes et al., 1971). This effect probably accounted for the $4 \%$ reduction in exercise cardiac frequency in rural children compared with urban children. The $11 \%$ higher exercise cardiac frequency of girls compared with boys, after allowing for fat-free mass, might have resulted from culturally determined sex differences in physical activity, boys being more active than girls.

The greater chest circumference of rural boys than that of urban boys, after allowance for sitting height and subscapular skinfold thickness, probably indicated a superior musculoskeletal development of the thorax in rural children. This would permit the rural boy to achieve a greater vital capacity, and it is interesting to note that inspiratory capacity was positively related to fatfree mass within children of African descent (Table 9). In contrast, residual volume showed no urban-rural difference.

The overall relationships of exercise cardiac frequency with vital capacity, total lung capacity, and transfer factor were probably expressions of an integrated response by the oxygen transport system to those inherited and acquired characteristics which affect the physical and physiological dimensions of its cardiorespiratory components. These include sex and habitual physical activity in the case of vital capacity, and habitual physical activity in the case of total lung capacity. The absence of a significant sex difference in total lung capacity is not in accord with the findings of Cotes et al. (1973a), who found this to be larger in boys than in girls of European descent.

This study failed to demonstrate any significant increases in either the transfer factor or its components in rural children, despite the existence of an increased total lung capacity in this group and the occurrence of an inverse association between the transfer factor and exercise cardiac frequency. The explanation of these findings was not clear but might have been related to the relatively large variability of transfer factor and its sub-divisions compared with that for total lung capacity. Table 5 shows that, for example in urban boys, the coefficient of variation (standard deviation expressed as a percentage of the mean value) for total lung capacity was $14 \%$ compared with $22 \%$ for transfer factor, $32 \%$ for the diffusing capacity of the alveolar capillary membrane, and $41 \%$ for alveolar capillary blood volume. Similar findings are also apparent for the other groups in Table 5. This relatively large variability of the gas transfer indices was probably due in part to other unidentified sources of biological variation (including haemoglobin concentration) and in part to greater measurement error compared to that for lung volumes. It is possible that, had these other sources of variability been identified and controlled, an urban-rural difference in gas transfer ability would have emerged.

In summary, these results support those of others cited in the introduction which suggest that habitual vigorous physical activity in childhood increases the vital capacity, total lung capacity, and transfer factor. There was some evidence that this effect was associated with an increased chest diameter. Growth and development of the structural and functional aspects of the oxygen transport system appears to be harmonious and consonant with the demand for muscular work.

We express our gratitude to the families in Jamaica whose co-operation made this study possible, and to the staff of Gordon Town All-age, Priory, and Providence schools for the interest shown and assistance offered to us. We also thank Mr. G. Berry for statistical advice.

\section{References}

Anderson, H. R., Anderson, J. A., and Cotes, J. E. (1974). Lung function values in healthy children and adults from highland and coastal areas of Papua, New Guinea. Papua and New Guinea Medical Journal, 17, 165-167.

Andrew, G. M., Becklake, M. R., Guleria, J. S., and Bates, D. V. (1972). Heart and lung functions in 
swimmers and nonathletes during growth. Journal of Applied Physiology, 32, 245-251.

Ashcroft, M. T., and Lovell, H. G. (1964). Heights and weights of Jamaican children of various racial origins. Tropical and Geographical Medicine, 16, 346-353.

Astrand, P. O., Engström, L., Eriksson, B. O., Karlberg, P., Nylander, I., Saltin, B., and Thoren, C. (1963). Girl swimmers. Acta Paediatrica, Supplement 147, 3 .

Bannister, R. G., and Cormack, R. S. (1954). Two low-resistance, low-deadspace respiratory valves (abstract). Journal of Physiology, 124, 4P-5P.

Beaven, G. H., Hornabrook, R. W., Fox, R. H., and Huehns, E. R. (1972). Occurrence of heterozygotes and homozygotes for the $\alpha$-chain haemoglobin variant Hb-J (Tongariki) in New Guinea. Nature, 235, 46-47.

Collins, M. M., McDermott, M., and McDermott, T. J. (1964). Bellows spirometer and transistor timer for the measurement of forced expiratory volume and vital capacity (abstract). Journal of Physiology, 172, 39p-41P.

Cotes, J. E. (1972). Response to progressive exercise: a three-index test. British Journal of Diseases of the Chest, 66, 169-184.

Cotes, J. E. (1975). Lung Function: Assessment and Application in Medicine, 3rd edition. Blackwell, Oxford.

Cotes, J. E., Dabbs, J. M., Daley, C., Hall, A. M., Johnson, G. R., Reed, J. W., and Saunders, M. J. (1971). Above-average exercise capacity in competition cyclists: relationship to body muscle (abstract). Journal of Physiology, 218, 63P-64P.

Cotes, J. E., Dabbs, J. M., Hall, A. M., Axford, A. T., and Laurence, K. M. (1973a). Lung volumes, ventilatory capacity, and transfer factor in healthy British boy and girl twins. Thorax, 28, 709-715.

Cotes, J. E., Saunders, M. J., Adam, J. E. R., Anderson, H. R., and Hall. A. M. (1973b). Lung function in coastal and highland New Guineans-comparison with Europeans. Thorax, 28 320-330.

Durnin, J. V. G. A., and Rahaman. M. M. (1967). The assessment of the amount of fat in the human body from measurements of skinfold thickness. British Journal of Nutrition, 21, 681-689.

Edwards, R. H. T., Miller, G. J., Hearn, C. E. D., and Cotes, J. E. (1972). Pulmonary function and exercise responses in relation to body composition in Trinidadian males. Proceedings of the Royal Society (London), Series B, 181, 407-420.

Ekblom, B. (1969). Effect of physical training in adolescent boys. Journal of Applied Physiology, 27, 350-355.

Goldman, H. I., and Becklake, M. R. (1959). Respiratory function tests: normal values at median altitudes and the prediction of normal results. American Review of Tuberculosis, 79, 457-467.
Greulich, W. W. (1957). A comparison of the physical growth and development of American-born and native Japanese children. American Journal of Physical Anthropology, 15, 489-515.

Harden, K. A., Wong, J. A., Carr, C.. Shelton, T. G., and Scott R. B. (1965). Timed vital capacity in children. American Review of Respiratory Diseases, 91, 869-873.

Harrison, G. A., Kuchemann, C. F., Moore, M. A. S., $\vec{\circ}$ Baju, T., Mourant, A. E., Godber, M. J., Glasgow, B. G., Kopec, A. C., Tills, D., and Clegg, E. J. $\vec{\omega}$ (1969). The effects of altitudinal variation in Ethiopian populations. Philosophical Transactions $\overrightarrow{\vec{x}}$ of the Royal Society, London, Series B, 256, 147182.

Harvey, R. G. (1974). An anthropometric survey of growth and physique of the populations of Karkar o Island and Lufa subdistrict, New Guinea. Philosophical Transactions of the Royal Society, London, Series B, 268, 279-292.

Huizinga, J. (1976). Comparative survey of African people living in the northern semi-arid zone: a search for a base line. In Population Structure and $\Phi$ Human Variation, edited by G. A. Harrison, Cam- $\vec{\bullet}$ bridge University Press. (In press.)

Huizinga, J.. and Glanville, E. V. (1968). Vital capacity and timed vital capacity in the Kurumba from Upper Volta. South African Journal of Science, 64, 125-133.

Ogilvie, C. M., Forster, R. E., Blakemore, W. S., and Morton, J. W. (1957). A standardized breath- D holding technique for the clinical measurement of the diffusing capacity of the lung for carbon monoxide. Journal of Clinical Investigation, 36, $1-17$.

Roberts. F. L., and Crabtree, J. A. (1927). The vital capacity of the Negro child. Journal of the American Medical Association, 88, 1950-1952.

Smillie, W. G., and Augustine, D. L. (1926). Vital ஹٕ capacity of the Negro race. Journal of the American Medical Association, 87, 2055-2058.

Standard, K. L., Desai, P., and Miall, W. E. (1969). A longitudinal study of child growth in a rural community in Jamaica. Journal of Biosocial Sciences, 1, 153-176.

Weiner, J. S., and Lourie, J. A. (1969). Human $D$ Biology: A Guide to Field Methods. Blackwell, 을. Oxford.

Wright, B. M.. and McKerrow, C. B. (1959). Maxi- S mum forced expiratory flow rate as a measure of $\mathrm{N}$ ventilatory capacity. British Medical Journal, 2, స్ట 1041-1047.

Requests for reprints to: Dr. G. J. Miller, Caribbean Epidemiology Centre (Carec), P.O. Box 164, Port of $\square$ Spain, Trinidad. 